\title{
NOTES
}

\section{Yield Strain Behavior of Poly(ethylene terephthalate): Correlation with Yield Stress Behavior in Strain Rate, Temperature, and Structure Dependence}

\author{
Jung Yul LIM ${ }^{\dagger}$ and Sang Yong $\mathrm{KIM}^{*}$ \\ Musculoskeletal Research Laboratory, Center for Biomedical Devices and Functional Tissue Engineering \\ and Department of Orthopaedics and Rehabilitation, \\ College of Medicine, Pennsylvania State University, Hershey, PA 17033, U.S.A. \\ * School of Materials Science and Engineering, College of Engineering, \\ Seoul National University, Seoul 151-742, Korea
}

(Received April 22, 2004; Accepted June 17, 2004; Published September 15, 2004)

KEY WORDS PET / Yield Strain / Yield Stress / Activation Volume / Structure-Property Relations / [DOI 10.1295/polymj.36.769]

Studies on the mechanical properties of polymers such as yield behavior have been the keys to successful use of polymers in various mechanically functional purposes. The yield behavior of polymers has been investigated by using polymers with varying structure (copolymer structure and composition, ${ }^{1,2}$ amorphous or crystalline, ${ }^{3,4}$ differential orientation and crystallinity ${ }^{5,6}$ presence of functional linkage, ${ }^{7}$ etc.). Strain rate and temperature have been the experimental parameters in those studies, as polymeric molecules display temperature and rate dependent phenomena. On the nature of the yield behavior of polymers, there have been reported a variety of phenomenological descriptions and molecular interpretations. One is to correlate the yield behavior with secondary mechanical relaxation behavior. ${ }^{2,6-8}$ It is based on the general understanding that such relaxations mediate macroscopic mechanical properties. We previously observed for oriented, semicrystalline poly(ethylene terephthalate) (PET) that $\tan \delta$ maxima of both primary and secondary relaxations are linear increasing functions of the activation volume calculated by the Eyring's yield model. ${ }^{6}$

All the above researches have focused mainly on the yield stress with no particular interest on the yield strain. In practical cases in mechanical applications, however, an elongational limit before the onset of a plastic deformation is also critical. To our knowledge, only one article can be found in the literature focusing on the yield strain, ${ }^{9}$ in which it was reported that there is a transition in the yield strain for polyethylene at a temperature where a change in deformation mode occurs from elastic-plastic to viscoelastic manner. In this study, we report the yield strain variation in PET as a function of stain rate, temperature, and PET structure to reveal the similarity and difference with the yield stress behavior. In addition, a novel dimensional analysis correlating the yield strain with the activation volume of the yield was proposed.

\section{EXPERIMENTAL}

PET samples with varying orientation and crystallinity were produced by the high speed melt spinning of high molecular weight PET (intrinsic viscosity of $0.98 \mathrm{dL} / \mathrm{g}$ ). PET was extruded at a constant mass flow rate and spun at a take-up velocity range of 2.5$5.5 \mathrm{~km} / \mathrm{min}$ to have different degree of melt draw ratio. Details of the melt spinning process and characterization methods are reported elsewhere,${ }^{10}$ and the properties of PET samples are listed in Table I. Tensile tests were performed using an Instron 4303 equipped with a temperature-controlling chamber. Measurements were done at various temperatures, e.g., 20,50 , and $75^{\circ} \mathrm{C}$. Filament sample was clamped under a pretension of $0.01 \mathrm{~g} / \mathrm{den}$ and placed inside the chamber preset to a desired temperature. The tensile test started after the thermal force generated in the sample became equilibrium (after $300 \mathrm{~s}$ ). ${ }^{11}$ To impose strain rate variation, the crosshead speed varied at $0.3-300 \mathrm{~mm} / \mathrm{min}$ at a constant gauge length of $50 \mathrm{~mm}$ corresponding to seven nominal strain rates from $10^{-4}$ to $10^{-1} \mathrm{~s}^{-1}$. Yield point was determined as the peak in the load-displacement curve. When the stress-strain curve shows no upper yield peak, e.g., for filaments displaying tensile behavior similar to drawn filaments, the $0.5 \%$ offset yield point calculation was used. Average of seven measurements is reported.

${ }^{\dagger}$ To whom correspondence should be addressed (Tel: +1-717-531-6696, E-mail: jlim@psu.edu). 
Table I. Properties and Eyring's activation parameters of PET

\begin{tabular}{|c|c|c|c|c|c|c|c|}
\hline \multirow{2}{*}{$\begin{array}{l}\text { Take-up } \\
\text { velocity } \\
(\mathrm{km} / \mathrm{min})\end{array}$} & \multirow{2}{*}{$\begin{array}{c}X \\
(\%)^{\mathrm{a}}\end{array}$} & \multirow{2}{*}{$\begin{array}{c}\text { Crystal size, } \\
(010) \\
(\AA)\end{array}$} & \multirow[t]{2}{*}{$\Delta n^{\mathrm{b}}$} & \multirow{2}{*}{$f_{\mathrm{a}}^{\mathrm{c}}$} & \multirow{2}{*}{$\begin{array}{c}T_{\mathrm{g}} \\
\left({ }^{\circ} \mathrm{C}\right)^{\mathrm{d}}\end{array}$} & \multicolumn{2}{|c|}{$\begin{array}{c}\text { Eyring's activation parameters } \\
\text { for yielding }\end{array}$} \\
\hline & & & & & & $\Delta H(\mathrm{kcal} / \mathrm{mol})^{\mathrm{e}}$ & $V\left(\mathrm{~nm}^{3}\right)^{\mathrm{f}}$ \\
\hline 2.5 & 2.6 & - & 0.045 & - & 78 & $55.7 \pm 0.13^{g}$ & $1.30 \pm 0.003^{h}$ \\
\hline 3 & 6.5 & 16.8 & 0.067 & 0.214 & 78 & $55.8 \pm 0.13$ & $1.13 \pm 0.003$ \\
\hline 3.5 & 13.4 & 33.0 & 0.089 & 0.266 & 80 & $58.1 \pm 0.11$ & $1.12 \pm 0.002$ \\
\hline 4 & 26.0 & 55.1 & 0.112 & 0.291 & 81 & $60.3 \pm 0.16$ & $1.09 \pm 0.003$ \\
\hline 4.5 & 32.7 & 57.6 & 0.124 & 0.308 & 82 & $62.1 \pm 0.13$ & $0.98 \pm 0.002$ \\
\hline 5 & 36.2 & 56.8 & 0.130 & 0.314 & 83 & $64.2 \pm 0.18$ & $0.91 \pm 0.003$ \\
\hline 5.5 & 37.2 & 57.1 & 0.132 & 0.313 & 84 & $64.2 \pm 0.16$ & $0.86 \pm 0.002$ \\
\hline
\end{tabular}

${ }^{\mathrm{a}}$ volume fraction crystallinity. ${ }^{\mathrm{b}}$ birefringence. ${ }^{\mathrm{c}}$ amorphous orientation factor. ${ }^{\mathrm{d}}$ glass transition temperature. ${ }^{\mathrm{e}}$ activation enthalpy. ${ }^{\mathrm{f}}$ activation volume. ${ }^{\mathrm{g}, \mathrm{h}}$ standard errors for the multiple regression with the Eyring's model.

\section{RESULTS AND DISCUSSION}

A comparison between the yield strain $\left(e_{\mathrm{y}}\right)$ and the temperature-normalized yield stress $\left(\sigma_{\mathrm{y}} / T\right)$ variations is shown as a function of strain rate and temperature dependence (Figure 1). PET structural effect is also shown from amorphous, less aligned sample (a) to highly crystalline and oriented structure (d). In the previous study, ${ }^{6}$ the yield stress variation was successfully fitted with the Eyring's model, where $R$ is a gas constant and $\dot{e}_{0}$ is a normalizing constant.

$$
\frac{\sigma_{\mathrm{y}}}{T}=\frac{R}{V}\left\{\frac{\Delta H}{R T}+\ln \frac{2 \dot{e}}{\dot{e}_{0}}\right\}
$$

As seen in the right panels, the plot between $\sigma_{\mathrm{y}} / T$ and the strain rate $(\dot{e})$ formed three parallel, linear isotherms between secondary and primary relaxation temperatures $\left(20,50\right.$, and $\left.75^{\circ} \mathrm{C}\right)$ at given strain rates of $10^{-4}-10^{-1} \mathrm{~s}^{-1}$. The activation enthalpy $(\Delta H)$ and activation volume $(V)$ of each PET samples were calculated from the regression of those three lines (Table I). The intercept and slope of the linear isotherms gradually increased with structural development. As a result, it was found that $\Delta H$ increased linearly with crystallinity suggesting a role of crystals as an energy barrier for yield, while $V$ decreased nonlinearly with crystallinity. The corresponding $e_{\mathrm{y}}$ results are shown in the left panels. For all given tensile test conditions and PET structure, $e_{\mathrm{y}}$ displayed a linear increasing trend with a logarithmic strain rate, which is the same as the $\sigma_{\mathrm{y}}$ variation. However, the strain rate dependence of $e_{\mathrm{y}}$ was steeper at lower ambient temperature. This is in sharp contrast with $\sigma_{\mathrm{y}}$ in that the strain rate dependence of $\sigma_{\mathrm{y}}$ was equivalent at ranges of temperature as parallel isotherms. With increasing orientation and crystallinity, both $e_{\mathrm{y}}$ and its strain rate dependence decreased continuously, which is contrary to the $\sigma_{\mathrm{y}}$ variation. This is understood considering the structural development during the molecular aligning process. The orientation during the PET
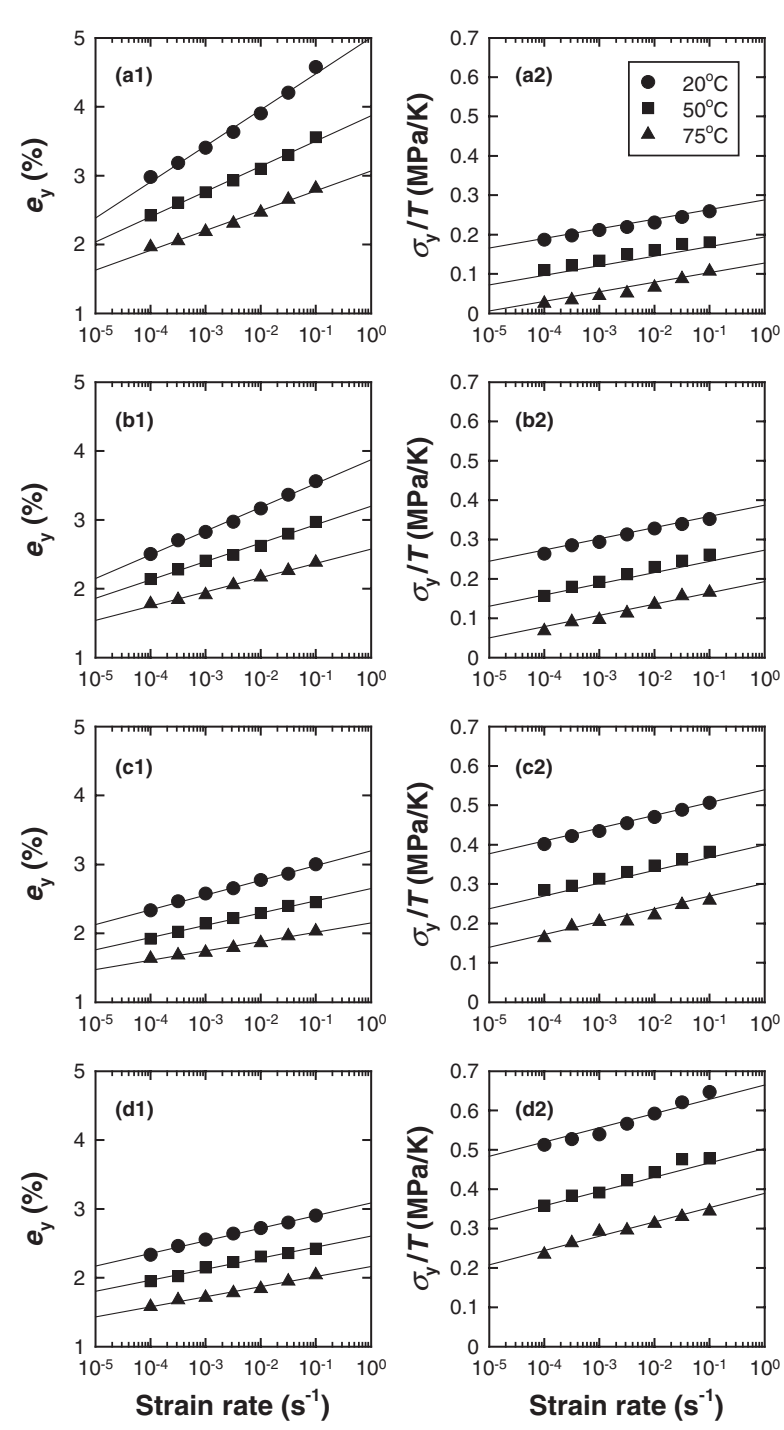

Figure 1. Variation in the yield strain (left panels) and the temperature-normalized yield stress (right panels) as a function of strain rate at various temperatures for PET filaments spun at 2.5 (a1, a2), 3.5 (b1, b2), 4.5 (c1, c2), and 5.5 (d1, d2) km/min, respectively. For the yield strain data, linear regression lines were drawn for each temperature without any formulation, while regression using the Eyring's equation 1 was drawn for the yield stress data. 

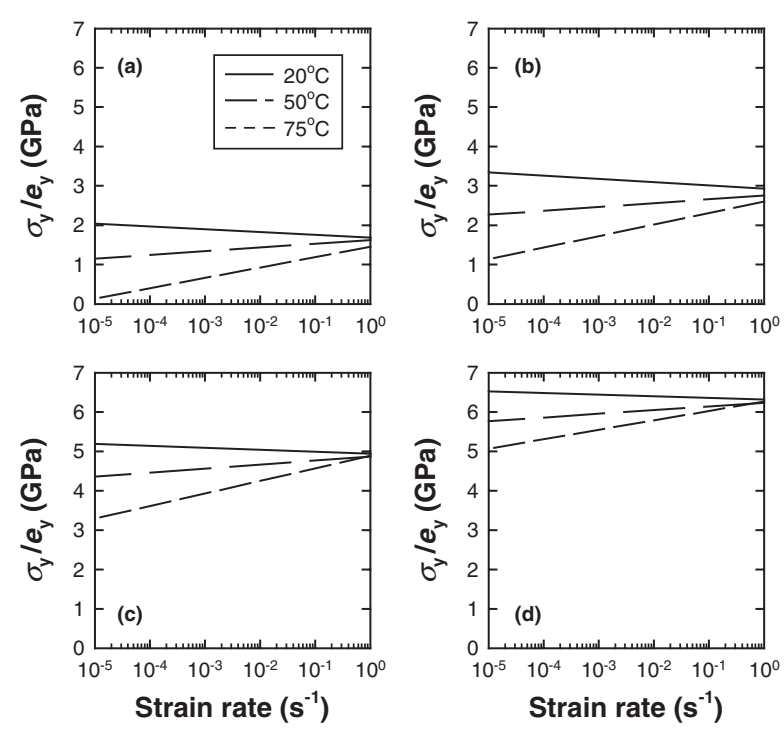

Figure 2. Variation in the ratio of the yield stress to the yield strain as a function of strain rate at various temperatures for PET filaments spun at 2.5 (a), 3.5 (b), 4.5 (c), and 5.5 (d) km/min, respectively.

fiber spinning or film drawing process not only shortens the amorphous chain length between the physical crosslinks, but also accelerates the orientation-induced crystallization which also decreases the chain length between the physical crosslinks. ${ }^{12}$ This renders the maximum possible molecular elongation up to the yield point shorter, which possibly makes its strain rate dependent variation small.

The similarity and difference between the non-independent $\sigma_{\mathrm{y}}$ and $e_{\mathrm{y}}$ variations may be reviewed in terms of modulus. Figure 2 plots $\sigma_{\mathrm{y}} / e_{\mathrm{y}}$ that is calculated from the two corresponding regression lines in Figure 1. For each strain rate and temperature, the yield stress value given by the regression with the Eyring's equation 1 is divided by the yield strain value given by the arbitrary linear regression. As the yield stress was determined from the upper yield point, this presentation of modulus is a secant modulus up to the yield point (slope from the origin of the stress-strain curve to the upper yield point) but not a Young's modulus (the initial tangential slope of the stress-strain curve). It was found that the higher the temperature, the higher the strain rate dependence of $\sigma_{\mathrm{y}} / e_{\mathrm{y}}$. This is an alternative presentation of the above observation that the strain rate dependence of $e_{\mathrm{y}}$ decreased with increasing temperature under the same strain rate dependence of $\sigma_{\mathrm{y}}$. Other $\sigma_{\mathrm{y}} / e_{\mathrm{y}}$ variation results follow the general, reported results on the Young's modulus, ${ }^{13}$ e.g., $\sigma_{\mathrm{y}} / e_{\mathrm{y}}$ was lower at higher temperature but higher for more developed structure. A slightly negative strain rate dependence observed for $20^{\circ} \mathrm{C}$, which is unusual, originates from the secant modulus calculation at the load maximum but not from the in- trinsic material properties. For polymers including PET, the stress-strain curve displays an initial linear, elastic region, a gradual deviation from the linear line, a load maximum, a load drop, and a plastic deformation region. The upper yield point occurs after the deviation from the straight line. Therefore, the secant modulus calculation up to the upper yield point results in lower modulus value than the Young's modulus calculation. In our data, difference between Young's modulus and secant modulus was significantly large only for $20^{\circ} \mathrm{C}$ data, in which such a difference was larger at a higher strain rate test than that at a lower strain rate test. As a result, the secant modulus line for $20^{\circ} \mathrm{C}$ in Figure 2 became slightly negative with respect to the strain rate. For 50 and $75^{\circ} \mathrm{C}$, difference between two modulus calculations was small. Figures 1 and 2 suggest that formulating the strain rate and temperature dependence of the tensile modulus as $E=E(\dot{e}, T)$ can enable to predict $e_{\mathrm{y}}=e_{\mathrm{y}}(\dot{e}, T)$, or vise versa. Therefore, the strain rate and temperature dependences of three yield-related parameters are strongly dependent each other and also on the polymer crystallinity and orientation.

Examples of PET structural effect on $e_{\mathrm{y}}$ are shown in Figure 3. The strain rate dependence of $e_{\mathrm{y}}$ is low for PET having higher crystallinity and increased birefringence, as seen by the narrow band width at the applied strain rate of $10^{-4}-10^{-1} \mathrm{~s}^{-1}$. The band width decreased continuously from amorphous, less oriented to highly oriented, semicrystalline PET samples, with no typical transition behavior. It is, however, usually difficult to separate the effects of crystallinity and orientation for oriented semicrystalline PET due to the strain-induced crystallization. ${ }^{6,12}$

We propose a novel dimensional analysis (Figure 4) correlating $e_{\mathrm{y}}$ with the activation volume, $V$, obtained from the Eyring's plot. $V$ is defined as the swept volume in the yield process or the product of a cross-sectional area $(A)$ of coherently moving segments and a moving distance $(l)$ of the yield movement over a potential energy barrier, $\Delta H .^{2}$ This definition is too conceptual to assign a specific molecular motion for the
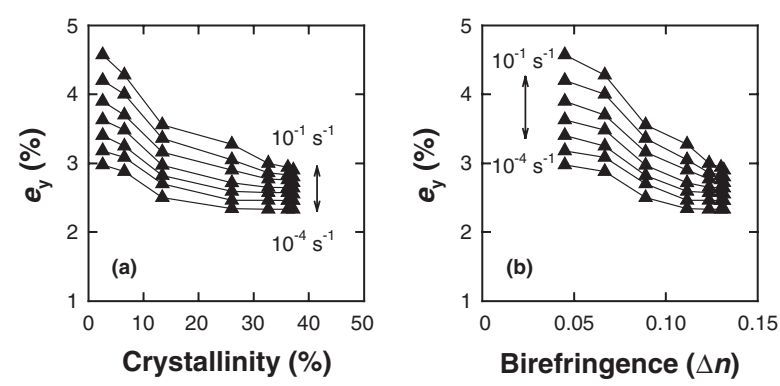

Figure 3. Variation of the yield strain as a function of crystallinity (a) and birefringence (b) of PET at various strain rate of $10^{-4}-10^{-1} \mathrm{~s}^{-1}$ and at temperature of $20^{\circ} \mathrm{C}$. 

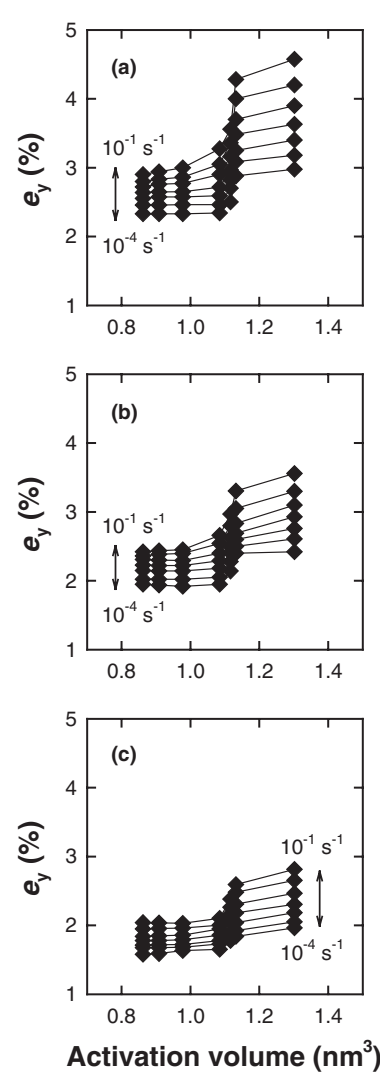

Figure 4. Plot of the yield strain vs. the activation volume of PET at various strain rate of $10^{-4}-10^{-1} \mathrm{~s}^{-1}$ and at temperature of $20^{\circ} \mathrm{C}(\mathrm{a}), 50^{\circ} \mathrm{C}(\mathrm{b})$, and $75^{\circ} \mathrm{C}$ (c).

yield. However, this instead allows a freedom to apply the model to a wide range of yielding phenomena covering even extremes of strain rate, temperature, experimental apparatus, and also polymers studied. ${ }^{3-6}$ This is because the Eyring's model groups all possible molecular displacements into two activation parameters, $V$ and $\Delta H^{2}$

Let us assume that the deformation up to the yield point is affine or the deformation on the molecular level is equivalent as that on the macroscopic level. This assumption is general for the elastic deformation region and is even utilized for theorization of rubber elasticity. ${ }^{14}$ Then, $e_{\mathrm{y}}$ (in macroscopic sense) can be regarded as a proportional measure of $l$ (in molecular sense). In such an $e_{\mathrm{y}}-V$ plot (Figure 4 ), one can observe a distinct transition in $e_{\mathrm{y}}$ at $V$ of $c a .1 .1 \mathrm{~nm}^{3}$. PET filaments spun at $3,3.5$, and $4 \mathrm{~km} / \mathrm{min}$ belong to this transition region, where a steep increase in crystallinity and orientation occurs (Table I). We thus propose that such a structural development at those take-up velocities makes specifically the molecular moving distance up to the yield short, while not much affecting the swept volume. Below and above the transition, the decrease in $V$ appears to originate mostly from the decrease in $A$ but not by the decrease in $l$, for $e_{\mathrm{y}}$ varies little. As for the strain rate dependence, one can also observe a similar transition at $V$ of $c a$. $1.1 \mathrm{~nm}^{3}$ by the substantial band width difference before and after the transition. The characteristic transition in $e_{\mathrm{y}}$ and its strain rate dependence can be seen most dramatically at measurement temperature of $20^{\circ} \mathrm{C}$. As higher temperatures of 50 and $75^{\circ} \mathrm{C}$, one can still see such transitions but in a less pronounced manner (Figure 4). This is predictable from the temperature sensitiveness result in Figure 1, that is, the less strain rate dependent $e_{\mathrm{y}}$ variation at higher temperatures results in less pronounced transition with respect to the activation volume at higher temperatures. The hypothetical $V$ of $1.1 \mathrm{~nm}^{3}$ is at least order of magnitude smaller than that of the individual crystallites (see the size of the PET crystallographic plane in Table I). This analysis using a single material parameter of $V$ may solve the above-mentioned difficulty in separating the effect of crystallinity and orientation. Furthermore, it may help to identify the molecular motion of the yield.

\section{CONCLUSIONS}

Oriented semicrystalline PET samples displayed a linear increase in $e_{\mathrm{y}}$ with logarithmic strain rate, similar to $\sigma_{\mathrm{y}}$. The strain rate dependence of $e_{\mathrm{y}}$ was smaller at higher temperature and for PET of increased crystallinity and orientation. This was in sharp contrast with $\sigma_{\mathrm{y}}$ in that the strain rate dependence of $\sigma_{\mathrm{y}}$ was the same at ranges of temperature and was higher for highly developed structure. The secant modulus plot indirectly described $e_{\mathrm{y}}$ and $\sigma_{\mathrm{y}}$ variations. A dimensional analysis revealed that PET had a distinct transition in both $e_{\mathrm{y}}$ and its strain rate dependence at the activation volume of $c a .1 .1 \mathrm{~nm}^{3}$.

Acknowledgment. We thank Kolon Ltd., Korea for the support in preparing and characterizing the PET samples.

\section{REFERENCES}

1. V. Gaucher-Miri and R. Seguela, Macromolecules, 30, 1158 (1997).

2. J. P. Chen, A. F. Yee, and E. J. Moskala, Macromolecules, 32, 5944 (1999).

3. J. S. Foot, R. W. Truss, I. M. Ward, and R. A. Duckett, J. Mater. Sci., 22, 1437 (1987).

4. Y. Liu and R. W. Truss, J. Polym. Sci., Polym. Phys. Ed., 32, 2037 (1994).

5. P. A. Botto, R. A. Duckett, and I. M. Ward, Polymer, 28, 257 (1987).

6. J. Y. Lim, H. J. Donahue, and S. Y. Kim, Macromol. Chem. Phys., 204, 653 (2003).

7. J. Liu and A. F. Yee, Macromolecules, 31, 7865 (1998).

8. L. Li and A. F. Yee, Macromolecules, 36, 2793 (2003). 
9. N. W. Brooks, A. P. Unwin, R. A. Duckett, and I. M. Ward, J. Polym. Sci., Polym. Phys. Ed., 35, 545 (1997).

10. J. Y. Lim and S. Y. Kim, J. Appl. Polym. Sci., 71, 1283 (1999).

11. J. Y. Lim and S. Y. Kim, J. Polym. Sci., Polym. Phys. Ed., 39, 964 (2001).
12. J. K. Keum, J. Kim, S. M. Lee, H. H. Song, Y.-K. Son, J.-I. Choi, and S. S. Im, Macromolecules, 36, 9873 (2003).

13. B. Crist, C. J. Fisher, and P. R. Howard, Macromolecules, 22, 1709 (1989).

14. U. W. Gedde, "Polymer Physics," Chapman \& Hall, London, U.K., 1995, chapt. 4. 